Session 1213

\title{
Changing the Culture: What's At the Center of Engineering Education?
}

\author{
Susan Ambrose \\ Eberly Center for Teaching Excellence \\ Carnegie Mellon University
}

\section{Introduction: Old and New Paradigms}

Over the past few years engineering educators have been talking about a paradigm shift which focuses more on learning than on teaching, on skills as well as knowledge, and which places students, not faculty, at the center of the educational process. ${ }^{[1,2,3]}$ This discussion recognizes that teaching does not directly cause learning, but rather the learner's attempts to perform cause learning, dependent upon the quality and timeliness of feedback and opportunities to use it. The diagram below captures the essence of the shift. ${ }^{[4]}$
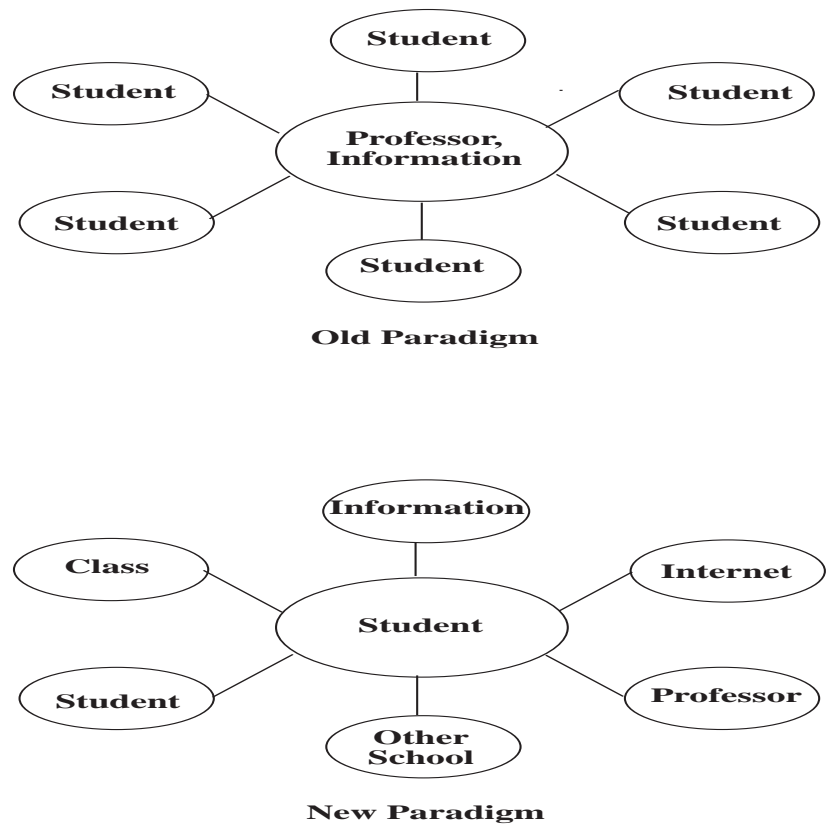

Figure 1. Learning Paradigms (adapted from Oblinger and Maruyama 1996) 
What does this shift entail and how can we help faculty adapt accordingly? It entails, in the long run, changing the culture -- actually changing many cultures -- from the culture of the academy to the culture of the institution, the department, and finally the culture of the classroom and those who reside there, faculty members and students.

This paper addresses only one of those aspects of change, the faculty and the need to enhance their understanding of the learner and the learning process. Inherent in any changes in faculty culture, however, are changes in the way they carry out their teaching responsibilities, and so students are affected, and hopefully student culture begins to change as well. In this paper we will first look at the culture of teaching which has been pervasive in higher education for many years and the traditional roles it defined, and then examine how the new paradigm reframes the definition of teaching and learning and the accompanying roles. Finally we will discuss who can facilitate this change to help faculty carry out their roles more effectively.

\section{What Has Defined the Culture Up To This Point, and How Is It Changing?}

The educational process for many years has placed the teacher and information at the center. Faculty were viewed as experts with a lot of knowledge to share, often making learning a noun, a thing to be possessed and passed along. Faculty had ultimate control of the classroom, typically lecturing while striving to cover as much information as possible. In this scenario, learning appeared to be more of a spectator sport.

There are many implications of this view of education. Students are passive in the process/classroom, like sponges soaking up information, an often-quoted and very misleading metaphor. Faculty try to cover as much information as possible, assuming that teaching and learning are synonymous. Neither proposition could be farther from the truth.

The new paradigm, as shown in figure 1, places students at the center of the educational process, and defines learning as a verb, a process in which students have the central role. It is evident through a number of studies and the ABET 2000 criteria that engineering education is moving toward this new paradigm. ${ }^{[1,2,3,5]}$ The implications of this model of education are numerous and well supported by recent research in cognitive psychology. Both faculty and students must rethink our respective roles and responsibilities in the process, and adapt our behavior accordingly. For faculty this may mean, among other things, rethinking our definitions of learning and teaching, rethinking the way we design and implement courses, and understanding more about our students and how they learn. For some faculty the changes aren't small - for example, they are learning what kinds of questions to ask, how to design more effective assignments, how to provide guided practice, and what kinds of feedback promote better learning.

The good news is that many campuses already have in place support structures to aid in the process. For years faculty development centers have provided services to faculty members creating or revising courses. People staffing these centers are often abreast of the latest research in cognitive science and education, and have experience taking some of the abstract concepts of learning and concretizing them for use in course design and implementation. The most important 
role these centers' staff can play is that of consultant, bringing to the table their expertise to share with domain experts, working toward a common goal. A concrete example might make the point more compelling. 


\section{$\underline{\text { 3. A Case in Point }}$}

Cognitive psychologists for many years have understood basic information processing. ${ }^{[6]}$

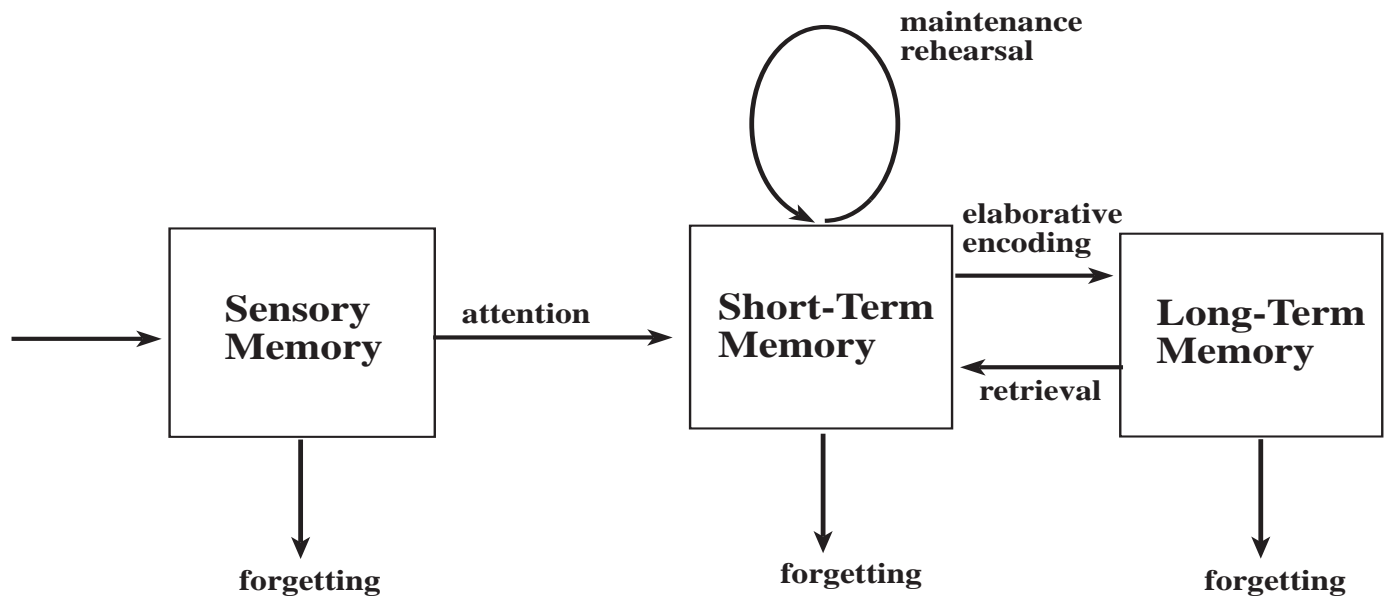

Figure 2. Basic Information-Processing Model of Memory (adapted from Atkinson and Shiffrin, 1968)

We know that students must choose to attend to information they see or hear (left side of the diagram), otherwise they lose it before it makes it way to short-term memory. Once in short-term memory, students have only 20-30 seconds to process the information if it is to make its way into long term memory. In order to acquire information in a lasting form, students need to actively do something with it (called elaborative encoding in the diagram), and they need to organize that information in a way that will allow them to retrieve it when necessary, and use it flexibly in a variety of appropriate settings/contexts. Often relevant information remains inert because students can't retrieve it. ${ }^{[7]}$

What does this mean for the way faculty should design and implement courses? Let me illustrate with two parts of the process, encoding and organization.

Faculty should understand what it takes to encode information into long term memory. For example, because prior knowledge is incredibly important in the learning process -- everything we see or hear filters through the lens of what we already know -- faculty need to understand what students already know. Often, what students know is incomplete or inaccurate, sprinkled with misconceptions. Unless we identify those inaccuracies or misconceptions, students continue to carry them around and eventually they hinder the learning process. Faculty might address this by administering a pre-test or knowledge-probe on the first day of class to gauge what students know as well as where they are weak. Making an assumption that students "should have learned $\mathrm{x}$ in course $\mathrm{y}$ because it was taught" may frustrate all involved down the road. Because prior knowledge is so important, faculty should try to link new information with familiar information; 
in part this is why analogies, metaphors, and "everyday" examples are important pedagogical tools.

Organizing material effectively is also key to the learning process, and often faculty don't explicitly address this issue. Figure 3 presents the best and worst case scenarios and argues that if we don't help students to understand how knowledge is organized in a discipline (concepts, principles, theories), they potentially won't make the right connections. ${ }^{[8]}$ Figures 3(a) represents fragmented knowledge with no organization; figure 3(b) indicates connected networks of concepts which are more coherent than the fragmented knowledge; and figure 3(c) shows a hierarchical knowledge organization. Without connections like those in 3(b) and 3(c), students' ability to use the information at appropriate times in appropriate ways is impeded.

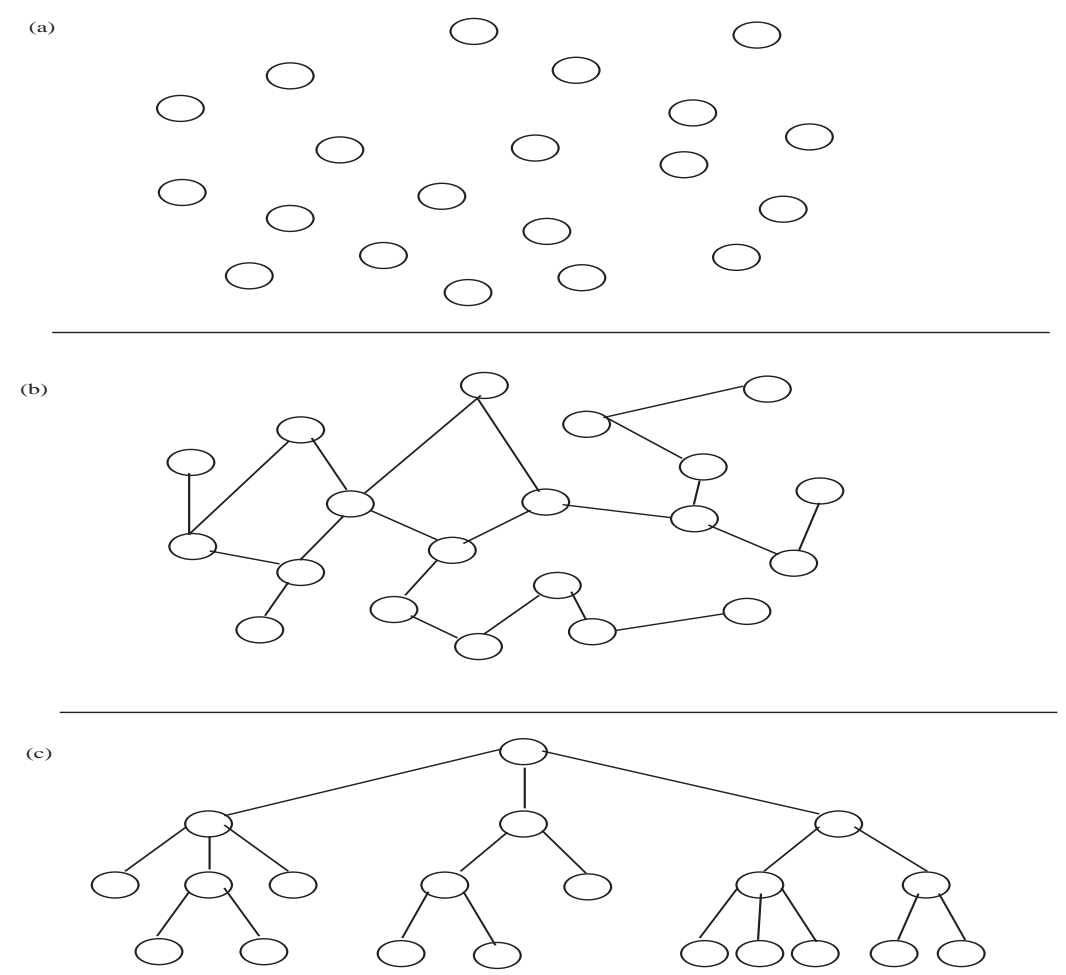

Figure 3: Schematic representations of various knowledge organizations. (a) Incoherent knowledge consisting of largely disconnected elements. (b) Knowledge elements linked to form a network. (c) Hierarchical knowledge organization.

Faculty should plan to both share with students their organizing schemes for the material in the course and in sections of the course as well as periodically check students' understanding of how all the pieces fit together. For example, simply asking students to diagramatically represent a body of information can indicate how students see the connections among the pieces. 
These are only two brief examples of what we know from cognitive psychology and how this information can impact learning; there are many more. For example, we now understand the key differences between expert and novice performance across a number of domains; we know more about the problem solving process and where students run into difficulty; we understand some common misconceptions students have in certain fields and how those misconceptions hinder learning; and we understand the value of writing to facilitate learning. Faculty can use this information as they design and implement courses to enhance deeper understanding on the part of their students.

\section{What Does This All Mean?}

As mentioned earlier, there are people on many campuses whose role is to help faculty design and implement their courses using cognitive and educational principles. These people are often found in faculty development centers, although in engineering some have emerged from engineering disciplines. The most effective of these are the people who function as consultants and customize their recommendations for course design and implementation not only to the relevant cognitive and educational principles but also to the targeted audience, course goals, and faculty member's style of teaching. The consulting relationship, I am convinced, works better with engineering colleagues than with many other colleagues for a number of reasons:

- Engineers understand the nature of the consulting relationship because it is pervasive in the engineering profession. As a result, they are not embarrassed to seek help, nor is their ego threatened.

- Engineers are used to collaborating with colleagues, particularly in research. They recognize and value the different skill set and knowledge base colleagues from other disciplines bring to the table.

- Engineers believe in the value of a team approach, for example to design new products or new systems. Typically engineering faculty have themselves experienced working in teams either as students or if they worked at any point in industry.

- Engineers appreciate a process - oriented model of learning which allows them to be more adaptive as teachers. They understand that knowing how a system works is central to making the process more efficient and effective.

If faculty development consultants tap into these natural predispositions and can help facilitate better understanding of the learner and the learning process, then engineering educators will be privy to information which can greatly advance/enhance their students' learning.

\section{Bibliography}

1. "Engineering Education: Designing and Adaptive System," National Research Council, National Academy Press, Washington, D.C., 1995. 
2. “Engineering Education for a Changing World," Engineering Deans Council and American Society for Engineering Education, Washington, D.C., 1994.

3. "Restructuring Engineering Education: A Focus on Change," National Science Foundation, 1995.

4. Oblinger, D.G. and Maruyama, M.K., Distributed Learning, CAUSE Professional Paper Series \#14, Boulder, CO., 1996.

5. “Engineering Criteria 2000," The Accreditation Board for Engineering and Technology, Baltimore, MD., 1998.

6. Atkinson, R.C., \& Shiffrin, R.M., Human memory: A proposed system and its control process. In K. Spence \& J. Spence (Eds.), The Psychology of Learning and Motivation, Vol. 2. New York: Academic Press. 1968.

7. Bransford, J.D., Sherwood, R.D. and Sturdevant, T.S., "Teaching thinking and problem solving" in Baron, J.B. and Sternberg, R.J. Teaching Thinking Skills: Theory and Practice, W.H. Freemand and Company, New York, 1987.

8. Reif, F., "Millikan Lecture 1994: Understanding and teaching important scientific thought processes," American Journal of Physics 63 (1), 1995.

SUSAN A. AMBROSE earned her Ph.D. (1986) in History from Carnegie Mellon, where she is Director of the Eberly Center for Teaching Excellence. She consults with faculty colleagues to provide help on course design and implementation based on sound cognitive and educational principles. She is also a 1998 Visiting Scholar for ASEE, Co-Director of Carnegie Mellon's NSF Engineering Education Scholars Workshop, and co-author of Journeys of Women in Science and Engineering: No Universal Constants (1997) and The New Professors Handbook: A Guide to Teaching and Research in Engineering and Science (1994). 